Rupantaran : A Multidisciplinary Journal

Vol. IV : pp 133-142, October, 2020

ISSN : 2091-0061

https://doi.org/10.3126/rupantaran.v4i1.34208

Research Management Cell (RMC)

Dhankuta Multiple Campus, Dhankuta

Tribhuvan University, Nepal

\title{
Meta Analysis on Knowledge, Attitude, Practice and Perception towards COVID-19 among Health Care Workers
}

\author{
Saraswati Basnet ${ }^{1}$ \\ Email: basnetsaru64@gmail.com
}

\section{Abstract}

Corona virus that causes illness ranging from the common cold to more severe diseases, is a newly discovered ribonucleic acid corona virus named 2019-nCoV.SARS-CoV-2. The aim of the meta-analysis is to evaluate the knowledge, attitude, practice and perception towards Covid-19 among health care worker (HCWs) by performing a systematic Meta analysis of related published literature. The Meta analysis was done only on involved sample of at least 327 to 1357 and total 4005 subjects and diverse research design were eligible among the 8 full-text articles. A formal extraction protocol was the PRISMA-P. Most of the HCWs were nurses, doctors and paramedic and females (54.9\%). Nearly half (44.4\%) were nurses, 36.8\% were doctors and only $18.8 \%$ were pharmacists \& technician. Most of (87.1\%) of the health care workers had good knowledge, almost all had positive attitude, $87.4 \%$ had positive practice and almost all had positive perception in terms of perception of Covid-19. Similarly less than one forth (12.9\%) of health care worker had poor knowledge, less than one forth (12.5\%) had poor practice respectively. The studies concluded that almost all of the HCWs had good knowledge, good practice, positive attitude and perception towards covid-19. A few HCWs had poor knowledge and practice, so training program could improve knowledge and practice.

Key Words: COVID-19, health care, knowledge, meta analysis, attitudes, practice perception

\section{Introduction}

Corona viruses are a large family of viruses that are known to cause illness ranging from the common cold to more severe diseases such as Middle East Respiratory

1. Ms. Basnet is at Lecturer of Tribhuvan University, Nursing Campus, Biratnagar. 
Syndrome (MERS) and Severe Acute Respiratory Syndrome (SARS). A novel corona virus $(\mathrm{CoV})$ is a new strain of corona virus that has not been previously identified in humans. This new virus and disease were unknown before the outbreak began in Wuhan, China, in December 2019 then World Health Organization (WHO) named COVID-19 which is the infectious disease caused by the most newly discovered corona virus causes coronavirus disease COVID-19. COVID-19 is now a pandemic affecting many countries globally (WHO, 2020).

In terms of symptoms, the WHO reported that more than $80 \%$ of COVID-19 patients showed mild symptoms and recovered without any medical intervention, approximately $20 \%$ of infected cases had a severe illness such as shortness of breath, septic shock and multi-organ failure, and it has been reported that an estimated $2 \%$ of cases can be fatal (WHO, 2020).

Corona virus disease (COVID-19) highly transmitted person to person had spread 213 countries and territories around the world. The worldometer report reported that a total of 25,291,285 confirmed cases of Covid-19 that originated from Wuhan, China and total of 848,557 deaths worldwide (WHO, 2020).

According to Shrestha, Pharma, Khanal\& KC (2020) the first case in Nepal was confirmed on 23 January 2020 when a 31-year-old student, who had returned to Kathmandu from Wuhan on 9 January, tested positive for the disease. The WHO Country office of Nepalhad updated situation on regional and global data as south-east Asia and Nepal all seven province (77districts) had total cases 32,676 (Nepal) and total death 157 and 35,33,807 (global) confirmed cases, 67,455 deaths respectively ( WHO Nepal,, 2020).

The health-care worker is at the center of the work system. All other system components, namely work tasks, technologies and tools, environmental factors, and organizational conditions, serve to enable the health-care worker to perform his or her role safely and effectively. Therefore, any measures to strengthen these system components must be worker-centric to facilitate acceptance and implementation (Gan, Lim \& Koh 2020).

About $89.51 \%$ of participants said that they had adequate knowledge of the COVID-19 epidemic. Moreover, significantly more physicians (38.30\%) obtained their relevant knowledge from medical journals compared with nurses. Among 311 respondents, $246(79.10 \%)$ reported having extensive knowledge, and 245 (78.78\%) expressed confidence in their ability to protect themselves and their patients but fewer psychiatrists were trained than psychiatric nurses (54.61\% vs. $72.94 \%$ ), a greater proportion of psychiatrists $(84.39 \%)$ expressed confidence in their ability to protect themselves and their patients than nurses (74.12\%) in the study (Shi,. et al. 2020). 
Study conducted on knowledge, attitude and practice among healthcare workers (HCWs) in Pakistan regarding coronavirus disease 2019 (COVID-19) among 386 Health Care Worker findings showed that HCWs have good knowledge (93.2\%,), a positive attitude [mean and standard deviation $(8.43 \pm 1.78)$ ] and good practice (88.7\%) regarding COVID-19. HCWs perceived that limited infection control material $(50.7 \%)$ and poor knowledge regarding transmission (40.6\%) were the major barriers to infection control. Regression analysis indicated that pharmacists were more likely to demonstrate good practice than other HCWs (odds ratio 2.247, 95\% confidence interval 1.11-4.55, $P=0.025$ ) (Saqlain, MunirRehman Ahmed Tahlir \& Mashhood, 2020).

\section{Methods and Materials}

Meta analysis design: This Meta analysis design was prepared by using secondary data of the all international and national published Journal, Report and articles. The objective of this study is to evaluate the knowledge, attitude, practice and perception of Covid-19 among health care workers by performing a systematic Meta analysis of related available published literature of COVID-19.

Eligibility Criteria: The inclusion criteria of study were developed with carefully examined published national and international research articles, report which was searched from the different database such as Google, Google scholar, Pub med, IRIS (WHO, Digital Publications), Scopus, Summon search through Hinary or Research4 Life. Since March 2020 to August 2020, the main focus on knowledge, attitude practice and perception towards Covid-19 among health Workers. The Meta analysis was done only on; a) English language b) involved sample of at least 327 to 1357 subjects and diverse research design were eligible. To retrieve articles related to objectives of interest, the following key words or terms were used to search the electronic database as corona virus, knowledge, attitude, practice and perception, corona virus or COVID-19. All full text articles on knowledge, attitude, practice and perception toward covid-19, outcome related studies among health care workers. Hand-searched (manual search) of the reference lists of all identified studies and key journals in the related field was developed.

Exclusion Criteria: The articles related to unreliable data, incomplete information, experimental methodological studies and randomized trial were extracted from data.

Search Strategy: The research articles on knowledge, attitude and perception of health with COVID-19 were searched through the electronic database as Google, Google Scholarly Pubmed, IRIS (WHO, Digital Publications), Scopus, Summon search through Hinary or Research4 Life base literature review of 20 research articles. The 
eligible articles were included as cross sectional study, comparative study, perspective studies, and studies for systematic reviewed. The sample size was included 327 to 1357 and 4005 Health Care Workers were total sample sizes of 20 articles for Meta analysis. In this analysis that focused on health workers' knowledge attitude practice and perception towards covid-19 which were searched from April 2020 to August 2020. About more than 20 reports were reviewed thoroughly and capture the required theme. A Preliminary Analysis and searched article's study period was ranging form1month to 3 months to less than 1year.

\section{Data extraction and analysis and synthesis}

The total 20 articles which were published from December 2019 to August 2020 were searched through the search engine i.e. Google, Scholarly Google Pub med, IRIS (WHO, Digital Publications), Scopus, Summon search through Hinary or Research4 Life Data base. While searching, the main key words were used as knowledge, attitude and perception on Corona virus (COVID-19) "and" "or" health workers. Health Care workers (HCWs) means includes doctors, nurses and pharmacist and other technical personnel's. Knowledge, attitude practice and perception of Covid-19 were measures areas of definition, risks, signs and symptoms and mode of transmission, treatment and prevention in different studies in full text articles. A formal extraction protocol (selection process) follows the PRISMA-P (Preferred Reporting Items for Systematic Review and Meta analysis Protocol) work flow which was used by Moher D, et al. 2015 which were checked and revised two or three time for consistency and reliability of the data. Among 20 articles, 12 articles were excluded from the protocol for following reason i.e. not relevant, total result not available eligibility and inclusion criteria or content related topic of this analysis not available. The Meta analysis included only studies in which the knowledge, attitude practice and perception towards the COVID-19 among Health care Workers. Others 12 articles were excluded because the data were not complete and comparable. Only 8 full text articles related to knowledge, attitude, perception of covid-19 among health care workers were included in manual for analysis but other vague information about the participants, interventions, experimental methodological findings were extracted from the protocol. The total sample sizes were 4005 health Care workers of 8 Full text articles included and other samples excluded from the protocol. Manual analysis was done among eligible articles included on level of knowledge, attitude and perception of covid-19 among Health Care Workers.

\section{Results and Discussion}

Overall results of the Meta analysis: Overall 8 full text articles were thoroughly reviewed and done Meta analysis on knowledge, attitude practice and perception of 
COVID-19 among 4005 health care workers. Most of the health care workers were nurses, doctors and paramedic. More than half (54.9\%) of health care workers were females and less than half (45.4\%) were males health care workers.Nearly half (44.4\%) of health care workers were nurses, less than half $(36.8 \%)$ were doctors and only $18.8 \%$ of HCWs were paramedics (pharmacists \& technician). $87.1 \%$ of HCWs had good knowledge, almost of the health care worker had positive attitude and $87.4 \%$ of HCWs had positive practice in terms of perception of Covid-19, almost of the health care worker had positive perception. Similarly less than one forth $(12.9 \%)$ of health care workers had poor knowledge, less than one forth (12.5\%) of HCWs had poor practice respectively. A few health care workers had negative attitude and negative perception towards covid-19. In most of the studies show that mean knowledge and practice scores were significantly associated with job descriptions of healthcare workers ( $\mathrm{p}$ value $-0.000,0.007$, respectively) with highest mean knowledge scores among doctors $(23.70 \pm 4.48)$ and highest mean practice scores among health assistants (15.10 \pm 3.61$)$ (Nepal et al., 2020).

\section{National wide meta analysis on knowledge, attitude practice and perception of COVID-19 among 4005 health care worker}

The survey conducted among 414 Health Care Workers (HCWs) in Pakistan found that the majority of HCWs have good knowledge $(93.2 \%, N=386)$, a positive attitude (mean 8.43) and good practice (88.7\%, $N=367$ ) towards COVID-19, 87.68\% $(N=363)$ of HCWs used social media as their main source of information, followed by radio and television $(45.89 \%, N=190)$ and seniors/other colleagues $(42.51 \%, N=176)$. The current finding of good knowledge $(93.2 \%, N=386)$ among HCWs which were regarding the symptoms, transmission and preventive measures of COVID-19. Chisquared analysis revealed that pharmacists $(94.7 \%, N=179)$ had greater knowledge than doctors $(93.3 \%, N=112)$ and nurses $(90.5 \%, N=95)$, but the difference was not significant $(P=0.383)$.in terms of attitude that identified a highly positive attitude (mean 8.43) among HCWs towards COVID-19 and a positive linear correlation found between knowledge and attitude in this study (Saqlain et al., 2020).

A descriptive cross-sectional study was done among 404 of HCWs at different hospital types in Fayoum Governorate, Egypt finding of knowledge assessment of the participants regarding COVID-19 knowledge mean scores were observed for male and female participants (18.68 \pm 2.89 and $18.24 \pm 2.56$, respectively) with no statistically significant difference. The mean knowledge score was significantly higher in the younger HCWs at age groups (20-30) and (30-39) than those in the older age groups $(p=0.014)$. Physicians then pharmacists had the highest knowledge score than other professions. The knowledge mean scores were significantly related to the level of education was higher education had significantly higher knowledge mean 
scores compared to those with lower levels of education and significantly increased knowledge score was in those working in direct contact with patients than others $(p<0.001)$ (Abdel Wahed, Hefzy\& Ahmed, 2020).

A cross-sectional survey was conducted from February $4^{\text {th }}$ to February $8^{\text {th }}, 2020$ across 10 hospitals in Henan province, China among 1357 Health Care Workers (doctors and nurses) findings shows that nearly one-half of the study respondents (46.5\%) were nurses, $36.5 \%$ were doctors and $17 \%$ were paramedics. Similarly $89 \%$ of HCWs had sufficient knowledge of COVID-19, more than $85 \%$ feared self-infection with the virus, and $89.7 \%$ followed correct practices regarding COVID-19. Doctors showed higher knowledge scores $(38.56 \pm 3.31)$ than nurses $(37.85 \pm 2.63)$ and paramedics $(36.72 \pm 4.82)$. Knowledge is a prerequisite for establishing prevention beliefs, forming positive attitudes, and promoting positive behaviors, and individuals' cognition and attitudes towards disease. The study shows that careful removal of protective equipment was found to be positively associated with a higher education level (OR: 2.12; 95\% CI: 1.39-3.24) and negatively with median work experience (0.72; 0.54-0.96) (Zhang et al, 2020).

A cross-sectional study was conducted between January 2020 and February 2020 in District 2 Hospital in China among 327 HCWs, finding shows that most of them were female $(74.0 \%)$ and only $26 \%$ of male, the highest percentage of HCWs were nurses $(70.9 \%)$ and the majority of them had less than 5 years experience (62.9\%). There were $98.2 \%$ of participants who knew the COVID-19 outbreak. The main sources of COVID-19 information were social media and the Ministry of Health website (91.1\% and $82.6 \%$, respectively). Almost (99.1\%) of participants knew that COVID- 19 is a virus, how to prevent transmission between humans, and that infected cases could result in death $(98.2 \%$, and $98.8 \%$, respectively). In terms of knowledge $88.4 \%$ of Health Care Workers had sufficient Knowledge where as only $11.6 \%$ HCWs had insufficient Knowledge. Similarly 93.3\% of HCWs had sufficient attitude where as $22.67 \%$ of HCW s had insufficient attitude. Occupation was correlated with knowledge and attitude scores, according to which pharmacists who showed higher levels of knowledge also found significantly higher levels of a positive attitude about COVID-19 compared to those who were employed as physicians, nurses and technical staff (8.55 vs. 8.33, 8.09, 7.80, $P<0.05)$, and (1.79 vs. 1.97, 1.85, 1.86, $P<0.01)($ Huynh, Nguyen,Tran, Vo, Vo, \&Phan, 2020). 
Table 1: Differences in knowledge, attitude and practice of healthcare workers by demographics by Countries

\begin{tabular}{|c|c|c|c|c|c|c|c|c|}
\hline \multirow[t]{2}{*}{$\begin{array}{l}\text { Charact } \\
\text { eristics }\end{array}$} & \multirow[t]{2}{*}{ Country } & \multirow[t]{2}{*}{$\begin{array}{c}\text { Total } \\
\text { Sample size }\end{array}$} & \multicolumn{2}{|c|}{$\begin{array}{l}\text { Knowledge } \\
\text { No. \& \% }\end{array}$} & \multicolumn{2}{|c|}{ Attitude } & \multicolumn{2}{|c|}{$\begin{array}{l}\text { Practice } \\
\text { No. \& \% }\end{array}$} \\
\hline & & & Good & poor & Positive & Negative & Good & poor \\
\hline $\begin{array}{l}\text { Overall } \\
\text { gender }\end{array}$ & & $\begin{array}{c}414 \\
(100)\end{array}$ & $386(93.2)$ & $28(6.8$ & 8.43 & 1.78 & $367(88)$ & \\
\hline male & & $\begin{array}{c}209 \\
(50.5)\end{array}$ & $\begin{array}{c}197 \\
(94.3)\end{array}$ & $12(5.7)$ & 8.41 & 1.77 & 187(89.5) & $22(10.5)$ \\
\hline female & Pakistan & $\begin{array}{c}205 \\
(49.5)\end{array}$ & $\begin{array}{c}189 \\
(92.2)\end{array}$ & $16(7.8)$ & 8.46 & 1.79 & $180(87.8)$ & \\
\hline \multicolumn{9}{|l|}{ Profession } \\
\hline Doctors & & $\begin{array}{c}120 \\
(29.98)\end{array}$ & $\begin{array}{c}112 \\
(93.3)\end{array}$ & $8(6.7)$ & 8.41 & 1.78 & $114(94.3)$ & $6(5.7)$ \\
\hline Nurses & & $\begin{array}{c}198 \\
(47.37)\end{array}$ & $95(90.5)$ & $10(6.8)$ & 8.64 & 1.88 & $96(91.4)$ & $9(8.6)$ \\
\hline Pharmacist & & $\begin{array}{c}189 \\
(46.55)\end{array}$ & $179(94.7)$ & $10(5.3)$ & 8.43 & 1.71 & 171(90.5) & $18(9.5)$ \\
\hline $\begin{array}{l}\text { overall } \\
\text { gender }\end{array}$ & & 327 & & & & & & \\
\hline $\begin{array}{l}\text { male } \\
\text { female } \\
\text { Profession }\end{array}$ & & $\begin{array}{c}85 \\
(26.0) \\
242 \\
(74.0)\end{array}$ & 289(88.4) & $\begin{array}{c}38 \\
(11.2)\end{array}$ & $\begin{array}{c}305 \\
(93.3 \%)\end{array}$ & $\begin{array}{c}22 \\
(6.7)\end{array}$ & $\begin{array}{l}\text { Suffici } \\
\text { Insuff }\end{array}$ & $\begin{array}{l}\text { ent \& } \\
\text { cient }\end{array}$ \\
\hline Doctors & China & $\begin{array}{c}43 \\
(13.1)\end{array}$ & \multicolumn{6}{|c|}{$\begin{array}{l}\text { The scores was higher levels of knowledge and positive attitude about } \\
\text { COVID-19 among pharmacists than physicians, nurses and technical } \\
\text { staff }(8.55 \text { vs. 8.33, 8.09, 7.80, } P<0.05) \text {, and ( } 1.79 \text { vs. } 1.97,1.85 \text {, } \\
1.86, P<0.01)\end{array}$} \\
\hline Nurse & & $232(70.9)$ & & & & & & \\
\hline $\begin{array}{l}\text { Pharmacist } \\
\text { \& Others }\end{array}$ & & $52(15.9$ & & & & & & \\
\hline Overall & & $407(100)$ & & & & & & \\
\hline \multicolumn{9}{|l|}{ Gender } \\
\hline male & Egypt. & $206(50.6)$ & & & & & & \\
\hline female & & 201(49.4) & & & & & & \\
\hline \multicolumn{9}{|l|}{ Profession } \\
\hline doctors & & $127(31.2)$ & $127(100)$ & & & & & \\
\hline Nurses & & $102(25.1)$ & & & & & & \\
\hline $\begin{array}{l}\text { Pharmacist } \\
\text { \& others }\end{array}$ & & $182(44.7)$ & & & & & & \\
\hline
\end{tabular}




$\begin{aligned} & \text { Overall } \\ & \text { Gender } \\ & \text { Male }\end{aligned}$
$\begin{aligned} & \text { 234(51..6) } \\ & \text { Female }\end{aligned}$ $\begin{aligned} & \begin{array}{l}78 \%(\mathrm{n}=353) \text { of the HCWs exhibited a } \\ \text { COVID-19. } \\ \text { Most of }(85.6 \%) \text { of HCWs agreed that ma } \\ \text { covering the nose and mouth while coughing, } \\ \text { could help to prevent COVID-19 transmission }\end{array} \\ & \begin{array}{l}\text { Professions } \\ \text { Doctors }\end{array} \\ & \begin{array}{l}\text { Other } \\ \text { HCWs }\end{array}\end{aligned}$

A web-based, cross-sectional study was conducted using a survey instrument to obtain responses from HCWs globally during the first week of March 2020study among 453 Health care workers findings shows that 234 (51.6\%) men and $219(48.3 \%)$ women. Most participants were below 44 years of age $(n=378,82.4 \%)$. The majority of participants were doctors (30.2\%). The level of knowledge about COVID-19 among HCWs. We identified significant knowledge gaps between doctors and other HCWs. For instance, 90 doctors $(65.7 \%)$ and 176 allied health workers $(55.7 \%)$ thought that COVID-19 originated from bats. The majority of the HCWs $(n=338$, $85.6 \%$ ) agreed that maintaining hand hygiene, covering the nose and mouth while coughing, and avoiding sick patients could help to prevent COVID-19 transmission. Most doctors agreed that COVID-19 could lead to pneumonia, respiratory failure, and death $(\mathrm{n}=115,84 \% ; \mathrm{P}=.04)$ and that supportive care is the only treatment option that is currently available $(\mathrm{n}=114,83.2 \% ; \mathrm{P}<.001)$. But participants' knowledge of questions related to the mode of transmission and the incubation period of COVID-19 was poor. Over $78 \%(n=353)$ of the HCWs exhibited a positive perception of COVID-19. The majority of HCWs knew that sick patients should share their recent travel history $(\mathrm{n}=420,92.7 \%)$, that flu vaccination is not sufficient to prevent COVID-19 ( $\mathrm{n}=411$, 90.7\%). About the COVID-19 is not fatal ( $\mathrm{n}=401,88.5 \%)$. In addition, $87 \%(\mathrm{n}=394)$ felt that washing hands with soap and water could help to prevent COVID-19 transmission; 84.3\% ( $\mathrm{n}=394) \mathrm{knew}$ that symptoms appear in 2-14 days; (Bhagavathula, AldhaleeiRahmaniMahabadi\&, Bandari, 2020).A cross-sectional study conducted among 353 healthcare workers from various health institutions located in Chitwan district of Nepal finding shows that $47 \%$ were nurses, $28.9 \%$ were doctors, $11.6 \%$ were health assistants, $2 \%$ were certified medical assistants, and the remaining $10.5 \%$ were categorized as others. More than half were females (58.9\%), age group of 16-29 years (67.1\%) and had work experience of less than 5 years $(62 \%)$. Almost all of healthcare workers obtained good to moderate knowledge and practice scores $(n=82.15 \%, 83.57 \%$, respectively) and had positive attitude scores $(n=90.93 \%)$. Mean score values were $21.65 \pm 4.71$ out of 33 in knowledge 
section, $8.07 \pm 1.49$ out of 13 in attitude section and $13.89 \pm 5.33$ out of 20 in practice section. Mean knowledge and practice scores were significantly associated with job descriptions of healthcare workers ( $p$ value $-0.000,0.007$, respectively) with highest mean knowledge scores among doctors (23.70 44.48$)$ and highest mean practice scores among health assistants $(15.10 \pm 3.61)$ (Nepal et al., 2020).

\section{Conclusion}

The different studies of knowledge, attitude practice and perception towards covid-19 among health worker concluded that most of the HCWs had good knowledge, good practice and positive attitude and perception towards covid-19. Although a few HCWs had poor knowledge and practice, training program could improve knowledge and practice. Mean knowledge and practice scores were significantly associated with job descriptions of healthcare workers ( $p$ value $-0.000,0.007$, respectively) with highest mean knowledge scores among doctors $(23.70 \pm 4.48)$ and highest mean practice scores among health assistants.

\section{References}

Abdel Wahed, W.Y., Hefzy, E.M.,\& Ahmed, M.I. (2002). Assessment of Knowledge, Attitudes, and Perception of Health Care Workers Regarding COVID-19: A Cross-Sectional Study from Egypt. J Community Health (2020). DOI https://doi. org/10.1007/s10900-020-00882-0

Bhagavathula AS,.Aldhaleei WA,.Rahmani J,.Mahabadi MA, \& Bandari DK (2020). Knowledge and Perceptions of COVID-19 among Health Care Workers: Cross-Sectional Study. JMIR Public Health Surveill 2020; 6(2):e19160 DOI: 10.2196/1916 from https:// publichealth. jmir.org/ 2020/2/e19160/

Gan, W.H., Lim, J.W., \& Koh, D. (2020). Preventing Intra-hospital Infection and Transmission of Coronavirus Disease 2019 in Health-care Workers. Journal of Science Direct (2020) 11(2):241-243. https:// doi.org/10.1016/j. shaw.2020.03.001. From https:// www. sciencedirect. com/science/ article/pii/S209379112030161X ¿via\%3Dihub\#!

Huynh, G,. Nguyen TNH,. Tran, VK,.Vo, KN,. Vo, VN, \& Phan LA,. (2020). Knowledge and attitude toward COVID-19 among health care workers at District 2 Hospital, Ho Chi Minh City. Asian Pacific Journal of Tropical Medicine, 13(6):260-265. From http:// www.apjtm.org/ article. asp? issn=1995-7645;year=2020; volume= 13 ; issue $=6$; spage $=260$; epage $=265$; aulast $=$ Huynh

Moher, D,. Shamseer, L,. Clarke, M,.\& Ghersi, D,. (2020). Preferred reporting items for systematic review and meta-analysis protocols (PRISMA-P) 2015 statement. Journal of Biomedical Center [Internet] 1 (2015). [Cited on Augast, 2020. Available from https:// systematicreviewsjournal. biomedcentral. com/articles/10.1186/2046-4053-4-1. 
Nepal, R,.Sapkota, K,.Poudel P., Adhikar, B,.Poudel N,.Sapkota, K., \& Nepal R,. (2020). Knowledge, attitude and Practice regarding Covid-19 among health workers in Chitwan, Nepal. Research Square, Journal of Infectious Disease https://doi.org/10.21203/rs.3.rs-26774/v1. From https:// www. Research square. com/article/rs-26774/v1

Saqlain, M,. Munir,.Rehman, S.U,. \& Ahmed, Z, (2020) Tahlir AH,. Mashhood M, Knowledge, attitude, practice and perceived barriers among healthcare workers regarding COVID-19: a cross-sectional survey from Pakistan. Journal of Hospital Infection, 2020 ISSN: 0195-6701, (105) 3: 419-423: doi https//://doi. org/10.1016/j.jhin.2020.05.007. fromhttps://www journal fhospitalinfection. com/article/S0195-6701(20)30238-3/fulltex.

Shi Y,.Wang J,. Yang Y,.Wang Z,.Wang G,.Zhang K,. \& Hashimoto (2020). Knowledge andattitudes ofmedicalstaffinChinesepsychiatrichospitalsregarding COVID-19. Brain, Behaviour\& Immunity-Health Open Access April 2020, (4): 100064. from https:// www.sciencedirect.com/science/article/pii/S2666354620300296.

Shrestha, S,.Pharma D,.Khanal, P,. \& K.C, B., (2020). Nepal's First Case of COVID-19 and public health response. Journal of Travel Medicine 2020 May 18;27(3):taaa024. doi: 10.1093/jtm/taaa024. From https://www. ncbi.nlm.nih. gov/pmc/ articles/ PMC7107523/

The Kathmandu Post (August 30, 2020). https://kathmandupost.com thmandupost. com/health/2020/08/09/nepal-s-covid-19-toll-reaches-75-with-two-moredeaths-380-new-cases-confirmedhttps://en.wikipedia.org/wiki/COVID-19_ pandemic in Nepal.

WHO (2020). Question and Answer. Zeneva: WHO. From http://www.emro.who. int/health-topics/corona-virus/questions-and-answers.html.

WHO (2020). WHO Director-General's opening remarks at the mission briefing on COVID-19. Online. Retrieved on March1, 2020 from: https://www.who. int/dg/ speeches/ detail/who-director-general-s-opening-remarks-at-themission- briefing-on-covid-19

WORLDOMETER (2002). Ovid-19 coronavirus pandemic LastUpdate August 30, 2020. https://www.worldometers.info/coronavirus/Sunday,.

Zhang, M., Zhou, M., Tang, F., Wang, Y., Nie, H., Zhang, L., \& You, G. (2020). Knowledge, attitude, and practice regarding COVID-19 among healthcare workers in Henan, China. Journal of Hospital infection 105(2); 183-187: https://doi.org/10.1016/j.jhin.2020.04.01. fromhttps://www. sciencedirect. com/ science/ article/pii/S0195670120301870\# 